\title{
A day in the life
}

The cost of health care in the United States (U.S.) and many other countries is a major issue of public concern, especially as these costs continue to rise. For example, U.S. health care spending increased by $4.3 \%$ to $\$ 3.3$ trillion in 2016, which is roughly equivalent to $\$ 10,348$ per person (1). At the current rate of growth, total spending on health care in the U.S. will account for $20 \%$ of the overall economy by the year 2026 (2). According to data from the Organization for Economic Cooperation and Development (OECD), the U.S. spends far more on health care compared to countries such as Australia, Canada, France, Germany, Japan, and the United Kingdom, primarily due to higher prices, higher administrative costs, and greater utilization of medical technology $(3,4)$. Unfortunately, greater spending does not translate to better outcomes. Despite spending almost twice that of other countries on health care, the U.S. fares worse than these other countries in regards to traditional quality outcome measures, such as infant mortality and life expectancy (5-7). Part of the issue may be that the U.S. spends its money in the wrong place- the U.S. spends far less on social support services and public health compared to other countries (3,8-10). However, regardless of where the money is spent, the current trend is not sustainable. The U.S. health care system must identify ways to deliver more effective care (i.e., care that actually improves outcomes) at lower costs.

Any discussion on reducing the costs of health care has to address the care that is delivered in the intensive care unit (ICU) environment. If greater utilization of medical technology is partly to blame for higher U.S. health care spending, then the technology-rich environment of the modern ICU will be one area where there should be opportunities to reduce costs. ICU care accounts for a significant proportion of total hospital costs in both adults (11) and children (12-14). In fact, most studies suggest that ICU care represents between $17.4 \%$ and $39.0 \%$ of all hospital costs (11,15-17), approaching $1 \%$ of the total U.S. economy (11). There are several reasons to suggest that ICU expenditures may continue to rise. For example, medical care has improved significantly in the last few decades, such that individuals, especially children, with certain diseases that were once uniformly fatal are living longer, albeit with significant morbidity and with a growing dependence on technology and home medical equipment, such as long-term mechanical ventilation, dialysis, and nutritional support (18-21). These children disproportionately require care in the ICU $(22,23)$. Moreover, advances in critical care medicine in recent decades have allowed more patients to survive acute critical illness, creating a growing population of patients with so-called "chronic critical illness" (24-26). These patients require prolonged stays in ICUs, with lengths of stay often measured in weeks. Though these long-stay patients survive their initial intensive care stays, they still experience high mortality rates and substantial long-term morbidity $(25,27)$.

Given all of these factors, it is clear that the critical care delivery model that has developed over the last several years is no longer sufficient to meet the evolving demands of critically ill children (28-30). Critical care delivery needs to be more efficient, more patient- and family-centered, and more cost-effective. These new models of critical care delivery need to account for the changing needs of the patients, as well as the providers (31,32). New paradigms will force design considerations to incorporate critical care delivery beyond the four walls of the ICU (33) and throughout the continuum of care. Indeed, almost everything about pediatric critical care medicine has to change.

Despite the need for a dramatic shift in care delivery paradigms, a quick glimpse at what happens during a typical day in the pediatric ICU reveals that care delivery is, in fact, starting to evolve with the changing needs of critically ill children.

The pediatric intensivist just got hand-off from the on-call team about all the events and new admissions that happened overnight. She starts her day checking in with the charge nurse to review the scheduled admissions from the operating room (OR). The intensivist makes a note that one of the scheduled surgical procedures involves a fairly complex patient-this patient is going to be sick. Just then, her cell phone buzzes-it starts already! A 3-month-old child down in the resuscitation room of the emergency department (ED) was just placed on high-flow nasal cannula, but the ED physician thinks he might need to be tracheally intubated, "Can you come down and evaluate the infant?"

The intensivist tells the ED physician that she will be down, but at that moment, she receives another call on the transport phone. The Transport Team is going across town to one of the community hospital's ED to pick up a 3-year-old patient with cardiac arrest. The child spent most of her first year of life in the neonatal ICU (NICU) and has been admitted to the pediatric ICU (PICU) a couple of times over the last year. She is tracheostomy- and ventilator-dependent due to chronic 
lung disease and acquired subglottic stenosis as a result of prolonged tracheal intubation in the NICU. She quickly reviews a number of scenarios for the team to anticipate, then adds, "Okay, call me when you get there."

"Maybe with a little luck, I will be able to finish my cup of coffee before X-ray rounds begin", the intensivist thinks to herself. Just then, however, the Rapid Response pager beeps. It's the hospital's facility on the north side of town, which doesn't have a PICU. The team there is worried their 5-year-old asthmatic on continuous albuterol is getting worse. So she's off to the telemedicine center to remotely evaluate the child for potential transfer (and yet another transport) to the PICU at the main hospital. One more child to see, and daily rounds have yet to start! The intensivist, the PICU nurse practitioner, and a PICU nurse remotely evaluate the 5-year-old. After a short discussion, the ward team and Rapid Response Team collectively decide to keep the child at the remote facility for now. He seems to be breathing a little easier, and the intensivist will check on him again in an hour.

The PICU charge nurse finds the intensivist finishing her cup of coffee in the telemedicine center. "We just got the 5-minute call on the liver transplant patient. They should be here soon." The intensivist quickly finishes her coffee and leaves to meet the surgical team bringing the liver transplant patient back from the OR. "Oh, yeab", the PICU charge nurse calls out to the intensivist, "Don't forget we have a Quality Improvement Committee meeting this afternoon. We had a spike in our catheter-associated bloodstream infections (CLA-BSI) numbers last month."

The intensivist responds in the affirmative with a nod of her head. Before tossing her empty cup into the trash can, she picks up her cell phone and texts the PICU fellow and nurse practitioner to go ahead and start reviewing the morning X-ray films. She'll be there after getting hand-off from the surgical team. On the way, she looks over to see her 14-year-old patient who was cannulated for ECMO about three weeks ago for acute myocarditis and has since been converted to a ventricular assist device. The PICU Mobilization Team is helping her out of bed for her morning walk around the unit. The intensivist smiles and waves at her patient, thinking to herself, "Fust a day in the life..."

This issue of Translational Pediatrics presents a diverse collection of articles relevant to the practice of pediatric critical care medicine. Some topics will be familiar and serve as a current state review of pediatric critical care fundamentals. Others will challenge us to step outside the four walls of the ICU and view the continuum of pediatric critical care more broadly. With perspectives on health policy, work force challenges, pandemic planning, handoffs, and post-ICU transitions, among others, this issue highlights aspects of the changing pediatric critical care landscape. With increased understanding about these important topics, we become better equipped to change the care delivery system.

\section{Acknowledgements}

None.

\section{References}

1. Hartman M, Martin AB, Espinosa N, et al. National health care spending in 2016: Spending and enrollment growth slow after initial coverage expansions. Health Aff (Millwood) 2018;37:150-60.

2. Cuckler GA, Sisko AM, Poisal JA, et al. National health expenditure projections, 2017-26: Despite uncertainty, fundamentals primarily drive spending growth. Health Aff (Millwood) 2018;37:482-92.

3. Squires D, Anderson C. U.S. health care from a global perspective: Spending, use of services, prices, and health in 13 countries. Issue Brief (Commonw Fund) 2015;15:1-15.

4. Papanicolas I, Woskie LR, Jha AK. Health care spending in the United States and other high-income countries. JAMA 2018;319:1024-39.

5. Institute of Medicine (US) Committee on Quality of Health Care in America; Kohn LT, Corrigan JM, et al. editors. To Err is Human: Building a Safer Health System. Washington, D.C.: National Academies Press, 2000.

6. McGlynn EA, Asch SM, Adams J, et al. The quality of health care delivered to adults in the United States. N Engl J Med 2003;348:2635-45.

7. Mangione-Smith R, DeCristofaro AH, Setodji CM, et al. The quality of ambulatory care delivered to children in the United States. N Engl J Med 2007;357:1515-23. 
8. Bradley EH, Elkins BR, Herrin J, et al. Health and social services expenditures: Associations with health outcomes. BMJ Qual Saf 2011;20:826-31.

9. Bradley EH, Canavan M, Rogan E, et al. Variation in health outcomes: The role of spending on social services, public health, and health care, 2000-09. Health Aff (Millwood) 2016;35:760-8.

10. Bradley EH, Sipsma H, Taylor LA. American health care paradox - high spending on health care and poor health. QJM 2017;110:61-5.

11. Halpern NA, Pastores SM. Critical care medicine in the United States 2000-2005: An analysis of bed numbers, occupancy rates, payer mix, and costs. Crit Care Med 2010;38:65-71.

12. Chalom R, Raphaely RC, Costarino ATJ. Hospital costs of pediatric intensive care. Crit Care Med 1999;27:2079-85.

13. García S, Ruza F, Alvarado F, et al. Analysis of costs in a pediatric ICU. Intensive Care Med 1997;23:218-25.

14. Kanter RK. Post-intensive care unit pediatric hospital stay and estimated costs. Crit Care Med 2000;28:220-3.

15. Halpern NA, Pastores SM, Greenstein RJ. Critical care medicine in the United States 1985-2000: An analysis of bed numbers, use, and costs. Crit Care Med 2004;32:1254-9.

16. Halpern NA, Pastores SM, Thaler HT, et al. Critical care medicine use and cost among Medicare beneficiaries 1995-2000: Major discrepancies between two United States federal Medicare databases. Crit Care Med 2007;35:692-9.

17. Coopersmith CM, Wunsch H, Fink MP, et al. A comparison of critical care research funding and the financial burden of critical illness in the United States. Crit Care Med 2012;40:1072-9.

18. Graham RJ, Fleegler EW, Robinson WM. Chronic ventilator need in the community: A 2005 pediatric census of Massachusetts. Pediatrics 2007;119:e1280-7.

19. Cohen E, Berry JG, Camacho X, et al. Patterns and costs of health care use of children with medical complexity. Pediatrics 2012;130:e1463-70.

20. Zhu H, Das P, Roberson DW, et al. Hospitalizations in children with preexisting tracheostomy: A national perspective. Laryngoscope 2015;125:462-8.

21. Cohen E, Berry JG, Sanders L, et al. Status Complexicus? The Emergence of Pediatric Complex Care. Pediatrics 2018;141:S202-11.

22. Edwards JD, Houtrow AJ, Vasilevskis EE, et al. Chronic conditions among children admitted to U.S. pediatric intensive care units: Their prevalence and impact on risk for mortality and prolonged length of stay. Crit Care Med 2012;40:2196-203.

23. Chan T, Rodean J, Richardson T, et al. Pediatric critical care resource use by children with medical complexity. J Pediatr 2016;177:197-203.e1.

24. Kahn JM, Le T, Angus DC, et al. The epidemiology of chronic critical illness in the United States. Crit Care Med 2015;43:282-7.

25. Namachivayam SP, Alexander J, Slater A, et al. Five-year survival of children with chronic critical illness in Australia and New Zealand. Crit Care Med 2015;43:1978-85.

26. Shapiro MC, Henderson CM, Hutton N, et al. Defining pediatric chronic critical illness for clinical care, research, and policy. Hosp Pediatr 2017;7:236-44.

27. Nelson JE, Cox CE, Hope AA, et al. Chronic critical illness. Am J Respir Crit Care Med 2010;182:446-54.

28. Riley C, Poss WB, Wheeler DS. The evolving model of pediatric critical care delivery in North America. Pediatr Clin North Am 2013;60:545-62.

29. Russell CJ, Simon TD. Care of children with medical complexity in the hospital setting. Pediatr Ann 2014;43:e157-62.

30. Henderson CM, Williams EP, Shapiro MC, et al. "Stuck in the ICU": Caring for children with chronic critical illness. Pediatr Crit Care Med 2017;18:e561-8.

31. Vincent JL. Critical care - where have we been and where are we going? Crit Care 2013;17:S2.

32. Vincent JL, Creteur J. Paradigm shifts in critical care medicine: The progress we have made. Crit Care 2015;19:S10.

33. Hillman K. Critical care without walls. Curr Opin Crit Care 2002;8:594-9. 


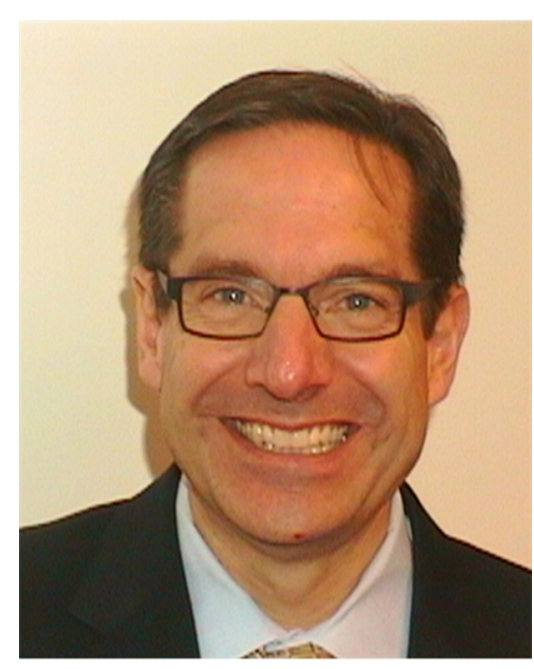

Derek S. Wheeler

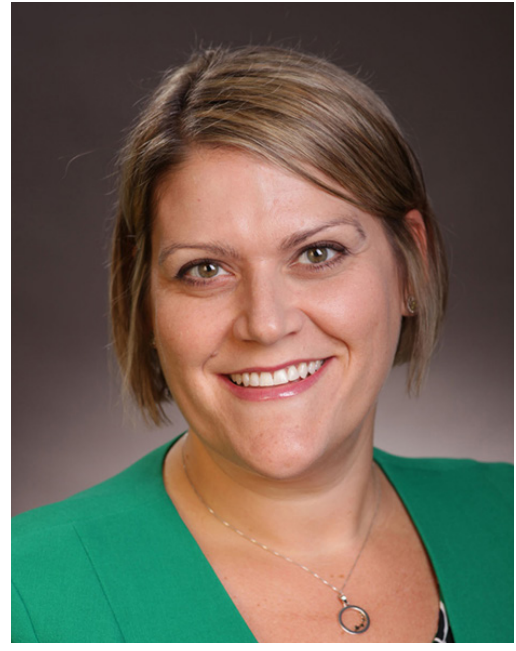

Erika L. Stalets

Derek S. Wheeler ${ }^{1,2}$

(Email: Derek.Wheeler@cchmc.org)

Erika L. Stalets ${ }^{1,2}$

(erika.stalets@cchmc.org)

${ }^{1}$ Division of Critical Care Medicine, Cincinnati Children's Hospital Medical Center, Cincinnati, OH, USA;

${ }^{2}$ Department of Pediatrics, University of Cincinnati College of Medicine, Cincinnati, OH, USA.

doi: $10.21037 /$ tp.2018.09.07

Conflicts of Interest: The authors have no conflicts of interest to declare.

View this article at: http://dx.doi.org/10.21037/tp.2018.09.07

Cite this article as: Wheeler DS, Stalets EL. A day in the life. Transl Pediatr 2018;7(4):242-245. doi: 10.21037/tp.2018.09.07 